\title{
Preferences for pig breeding goals among organic and conventional farmers in Sweden
}

\author{
A. Wallenbeck (D) - L. Rydhmer • H. Röcklinsberg • \\ M. Ljung • E. Strandberg • T. Ahlman
}

Received: 16 March 2015 / Accepted: 16 June 2015 / Published online: 30 June 2015

(C) The Author(s) 2015. This article is published with open access at Springerlink.com

\begin{abstract}
Organic and conventional pig farmers' preferences regarding breeding goal traits important in pigs were investigated using an advanced internet-based questionnaire. Farmers were asked what pig traits they spontaneously considered important, to rank 15 given traits and to weigh traits against each other given the estimated genetic change (calculated based on selection index theory). Organic and conventional farmers ranked both functional and production traits highly. For example, more than $70 \%$ of farmers from both production systems ranked piglet survival, fertility, sow longevity, leg health, feed conversion, piglet birth weight, piglet and slaughter pig growth as being of high or moderate importance (1-10/15). Litter size and shoulder ulcers were ranked higher by respondents from conventional farms, while parasite resistance and roughage consumption were ranked higher by respondents from organic farms. Regarding estimated desired genetic change, respondents from organic farms favoured health traits while conventional farmers favoured growth traits. In
\end{abstract}

\footnotetext{
A. Wallenbeck $(\bowtie) \cdot$ L. Rydhmer $\cdot$ E. Strandberg $\cdot$

T. Ahlman

Department of Animal Breeding and Genetics, Swedish University of Agricultural Sciences (SLU), Uppsala, Sweden e-mail: anna.wallenbeck@slu.se
}

A. Wallenbeck $\cdot$ H. Röcklinsberg

Department of Animal Environment and Health, SLU, Uppsala, Sweden

M. Ljung

Department of Urban and Rural Development, SLU, Uppsala, Sweden order to obtain genetic improvement in those traits, farmers gave low priority to carcass quality and litter size. Due to the variations in farmers' breeding goal trait preferences demonstrated here, it is clearly important to take farmers' preferences into consideration when developing future pig breeding strategies.

Keywords Swine $\cdot$ Breeding $\cdot$ Pig characteristics $\cdot$ Niche production $\cdot$ Production systems

\section{Background}

The market for pig meat changes continuously in response to changes in consumer preferences, societal values and political decisions. As new market trends develop, pig farmers adjust their production, generating new niche production systems. In most cases, the breeding goal of the genetic material used is not related to these production systems. Rydhmer et al. (2014) indicated a need for development of different breeding strategies for such contrasting production systems with added values (e.g. animal welfare and environmental impact). The requirements of different stakeholders in the food chain, e.g. farmers, retailers and consumers, need to be addressed in the development of breeding goals in order to improve the long-term sustainability of animal production (Gamborg et al. 2005). Moreover, development of sustainable breeding strategies for a specific animal production system (e.g. a niche production system) should start with identification of traits especially important for animals reared in that production environment, followed 
by investigation of the relative importance of different traits (Boelling et al. 2003). However, there is generally a lack of knowledge about stakeholder preferences within niche production systems.

Although all stakeholder groups are highly important in the process of developing sustainable breeding strategies for a particular production system, farmers have essential experience and knowledge of how animals function in practice and ultimately decide what animal material they want to use on their farm.

From an international perspective, all Swedish pig production systems can be considered niche production, with added values such as animal welfare (Bonneau et al. 2011). The main pig production system in Sweden (hereafter referred to as 'conventional production') complies with the relatively strict Swedish animal welfare laws, which in turn are based on societal expectations. For example, since the 1980 s, it has been forbidden to keep sows in crates, so sows are kept loose-housed in groups during the dry period (also applies in the EU since 2013) and individually loose-housed together with their piglets during farrowing and the 4-5-week-long suckling period. The main alternative pig production system in Sweden is organic production based on regulations for certification developed from basic principles concerning the environment and human and animal welfare (IFOAM 2005; KRAV 2014). These basic principles are reflected in the design of organic production systems, e.g. organic pigs are fed a high proportion of locally produced feedstuff, have access to outdoors and the piglets stay with the sow for longer than piglets in conventional production.

The overall aim of this study was to determine, compare and discuss Swedish conventional and organic farmers' preferences regarding breeding goal traits important for pig production. An advanced internet questionnaire was used to study (1) traits farmers spontaneously stated as important in pigs, (2) how farmers ranked given traits against each other and (3) what genetic changes farmers would like for different traits.

\section{Material and methods}

The analysis was conducted using an advanced internet questionnaire developed in a larger research project. In the project, the same methodology was used to assess dairy farmers' preferences as described by Ahlman et al. (2014). Invitations to complete an internet questionnaire on breeding goal traits important in pigs were sent to pig farmers via e-mail. E-mail addresses were retrieved from the databases of the Swedish Animal Health Service, the Swedish Rural Economy and Agricultural Societies and the Swedish organic certification organisation KRAV. In total, invitations were sent out to $522 \mathrm{pig}$ farmers, corresponding to approximately $50 \%$ of pig farmers in Sweden at that time. The questionnaire was open from 23 February to 30 March 2012. Swedish pig farmers generally have good computer skills, and farmers with e-mail addresses registered in the databases mentioned above were expected to check their e-mails on a weekly basis. The first invitation to the questionnaire was followed by two reminders at approximately 2-week intervals. The respondents could open the questionnaire several times as long as they did not click finish and submit their answers. Once submitted, their answers were recorded and each respondent's individual link to the questionnaire was closed.

Internet-based questionnaire

The questionnaire consisted of four parts, in which respondents were asked to the following:

1. State (in free text) traits they spontaneously considered important for their farm

2. Rank 15 given traits against each other

3. Weigh traits against each other given the estimated genetic change

4. Answer general questions about themselves and their farm

We estimate that it took between 15 and $45 \mathrm{~min}$ to answer the questionnaire.

\section{Part 1}

Respondents were asked to state traits they spontaneously considered important in pigs on their farm. The respondents used their own words to describe each trait in a separate textbox. Ten textboxes were available. Although the words used differed between respondents, the answers included only 12 traits in total. Respondents' statements were later transformed into binary classes (trait mentioned/not mentioned). All answers given by the respondents were included in this transformation. 
Table 1 Traits ranked by respondents listed in alphabetical order, description, units and phenotypic standard deviations $\left(s^{\mathrm{P}}\right)$

\begin{tabular}{|c|c|c|c|}
\hline Trait & Description given to the farmers & Units & $s^{\mathrm{P}}$ \\
\hline Disease resistance (DR) & More pigs without clinical symptoms & $\begin{array}{l}\% \text { of pigs on the farm not treated for } \\
\text { infectious diseases }\end{array}$ & 5 \\
\hline Feed conversion $(\mathrm{FC})$ & Better feed conversion & g growth/MJ ME in feed & 2.3 \\
\hline Fertility (FE) & $\begin{array}{l}\text { More sows with normal interval (max. } 7 \text { days) } \\
\text { between weaning and successful insemination }\end{array}$ & $\begin{array}{l}\% \text { of sows on the farm with } \leq 7 \text { days } \\
\text { between weaning and conception }\end{array}$ & 5 \\
\hline Growth of piglets (GP) & Higher growth & g/day & 40 \\
\hline Growth of slaughter pigs (GS) & Higher growth & g/day & 90 \\
\hline Litter size (LS) & Larger litters & Number born alive & 2.9 \\
\hline Leg health (LH) & Better leg health & Score, $1=$ bad to $5=$ good & 0.6 \\
\hline Meat quality (MQ) & More juicy meat, i.e. less drip loss & $\%$ liquid in meat & 2.2 \\
\hline Meat percentage (MP) & Higher meat percentage & $\%$ meat in carcass & 3 \\
\hline Parasite resistance $^{\mathrm{a}}(\mathrm{PR})$ & More pigs without internal parasite infections & $\%$ pigs on the farm without parasites & 5 \\
\hline Piglet survival (PS) & More surviving piglets, i.e. less piglet mortality & $\%$ live born surviving until weaning & 12 \\
\hline Piglet birth weight (PW) & Increased piglet weight & $\mathrm{kg}$ & 0.25 \\
\hline Roughage consumption ${ }^{\mathrm{a}}$ (RC) & Increased capacity to eat roughage & $\mathrm{kg} \mathrm{DM} /$ day & 1.5 \\
\hline Shoulder ulcers in sows (SU) & More sows without shoulder ulcers & $\%$ of sows without shoulder ulcers & 5 \\
\hline Sow longevity (SL) & Longer interval between first farrowing and culling & Days from first farrowing until culling & 350 \\
\hline
\end{tabular}

${ }^{a}$ Potential future breeding trait, not included in Scandinavian pig breeding goals in 2014

Part 2

Respondents were asked to rank 15 given traits against each other, from most to least important. The traits were chosen to represent both production traits and functional traits and also both traditional and potential future breeding goal traits (e.g. roughage consumption and parasite resistance, traits not included or phenotypically measured in current breeding programmes) (Table 1). Respondents were asked to imagine one superior breed that holds all the valuable traits in both dam and sire breeds and thereby represents the hybrid sows and terminal pigs in commercial production. All traits were defined so that an increase was favourable. The order in which the traits were presented to each respondent varied randomly between questionnaires, to prevent bias. The respondents had to rank all traits before they could continue to part 3 .

\section{Part 3}

Respondents were asked to weigh traits against each other, and the genetic change for each trait was estimated based on a selection index included in the questionnaire. This part of the questionnaire was more complicated to respond to than general questionnaires, and therefore an instruction video was included. Each respondent assigned weights to the five traits that respondent had ranked highest (1-5/15) in part 2, i.e. different traits were shown to different respondents. Each of the chosen five traits could be given a weight from 0 to 100 , and the weights given to all five traits had to add up to 100. The respondent allocated weights to the traits and, the expected genetic change was then calculated and displayed to respondent in the units presented in Table 1. It was possible to reallocate the weightings if the genetic change for the five traits was not acceptable. This procedure could be repeated indefinitely, and only the weights and genetic change given in the last run before submission were recorded. The traits ranked $6-15$ in part 2 were included in the selection index, but the genetic changes in these traits were not shown to the respondent. The weight of these traits was set to zero, and the correlated responses were calculated.

The genetic change presented was calculated based on selection index theory. The information was based on 400 half sibs per individual, with one measurement per trait. The intensity of selection was 2.421 (corresponding to $2 \%$ selected proportion). The descriptive parameters used are given in Table 2.

The genetic and phenotypic parameters used in the selection index were based on literature survey (Tables 1 
Table 2 Descriptive parameters used in the selection index

Number of observations per individual in information source

Number of individuals in information source

400

Influence of common environment on the trait

0

Relationship between the candidate for evaluation and individuals in information source

Intensity of selection

$0.26^{\mathrm{a}}$

$2.421^{\mathrm{b}}$

${ }^{a}$ Based on the assumption that information is available on the individual itself, approximately nine full sibs and 400 half sibs. This gives a genetic relationship to the information source of just above 0.25 , in this case estimated to be 0.26

${ }^{\mathrm{b}}$ Based on the assumption that $2 \%$ of the population is selected as parents of the next generation

and 3). These parameters include heritabilities for all the traits, providing information on the proportion of genetic contribution to the phenotypic expression of the trait. Estimates from Swedish production systems or from studies based on similar production conditions were prioritised. In cases where genetic and/or phenotypic parameters could not be found in the literature, parameters were derived from information about genetic parameters for similar traits and the underlying biological associations. The genetic and phenotypic correlation matrices developed were found to be positive definite, and no bending procedure was needed. Because of large variation in phenotypic variance between traits, phenotypic variances were converted to standardised values by dividing them by the corresponding genetic variance. The estimated genetic change was transformed to the original units before being presented to the respondents.

\section{Part 4}

Finally, the respondents were asked about farm characteristics such as production type (e.g. piglet and/or slaughter pigs), certification of production (i.e. organic or conventional) and basic information about themselves (e.g. gender and age).

Table 3 Genetic and phenotypic parameters used in the selection index

\begin{tabular}{|c|c|c|c|c|c|c|c|c|c|c|c|c|c|c|c|}
\hline Trait $^{\mathrm{b}}$ & DR & $\mathrm{FC}$ & $\mathrm{FE}$ & GP & GS & LS & LH & MQ & $\mathrm{MP}$ & PR & PS & PW & $\mathrm{RC}$ & SU & SL \\
\hline DR & 0.15 & 0.05 & 0.05 & 0.05 & 0.05 & 0 & 0 & 0 & 0 & 0.05 & 0.05 & 0 & 0 & 0 & 0.05 \\
\hline $\mathrm{FC}$ & 0.1 & 0.13 & 0 & 0.25 & 0.5 & 0 & 0 & -0.3 & 0 & 0.05 & 0 & 0 & 0.25 & 0 & 0 \\
\hline $\mathrm{FE}$ & 0.1 & 0 & 0.1 & -0.2 & -0.1 & -0.05 & 0 & 0 & -0.05 & 0 & 0 & -0.05 & 0 & 0 & 0.2 \\
\hline GP & 0.3 & 0.25 & -0.2 & 0.2 & 0.5 & -0.05 & 0 & -0.05 & -0.1 & 0.05 & 0.05 & 0.1 & 0.15 & -0.2 & 0.05 \\
\hline GS & 0.2 & 0.7 & 0 & 0.3 & 0.25 & -0.15 & -0.2 & -0.5 & -0.15 & 0.05 & -0.05 & 0.05 & 0 & 0 & 0 \\
\hline LS & 0 & 0 & 0 & -0.05 & -0.15 & 0.1 & 0 & 0 & -0.1 & 0 & -0.4 & -0.3 & 0 & -0.1 & 0.05 \\
\hline LH & 0 & 0 & 0 & 0 & 0 & 0 & 0.2 & 0 & -0.2 & 0 & 0.15 & -0.1 & 0 & 0.05 & 0.2 \\
\hline MQ & 0 & 0 & 0 & -0.05 & -0.15 & 0 & 0 & 0.16 & -0.3 & 0 & 0 & 0 & 0 & 0 & 0 \\
\hline MP & 0 & 0 & 0 & 0 & 0 & -0.1 & -0.05 & -0.1 & 0.5 & 0 & 0 & -0.05 & 0 & 0 & 0 \\
\hline PR & 0.1 & 0.1 & 0 & 0.2 & 0.2 & 0 & 0 & 0.05 & 0 & 0.2 & 0 & 0 & 0 & 0 & 0 \\
\hline PS & 0.1 & 0 & 0 & 0 & 0 & -0.3 & 0 & 0 & 0 & 0 & 0.04 & 0.4 & 0 & 0 & 0 \\
\hline PW & 0 & 0 & 0 & 0.1 & 0.3 & -0.3 & 0 & 0 & 0 & 0 & 0.3 & 0.1 & 0.15 & -0.2 & 0 \\
\hline $\mathrm{RC}$ & 0 & 0 & 0 & 0.2 & 0.1 & 0 & 0 & 0 & 0 & -0.1 & 0.1 & 0.15 & 0.2 & 0.05 & 0 \\
\hline SU & 0 & 0.05 & 0 & -0.2 & 0 & -0.1 & 0.1 & 0 & -0.2 & 0 & 0 & -0.2 & 0.1 & 0.2 & 0.05 \\
\hline SL & 0.3 & 0 & 0.1 & 0.1 & 0 & 0.15 & 0.05 & 0 & 0 & 0 & 0.1 & 0.1 & 0.1 & 0.1 & 0.05 \\
\hline
\end{tabular}

Heritabilities on the diagonal, genetic correlations above the diagonal and phenotypic correlations below the diagonal

${ }^{a}$ Bereskin (1979), Lundeheim (1979), Stewart and Hale (1988), Webb (1989), Stern et al. (1995), Knapp et al. (1997), ten Napel et al. (1998), Hall et al. (1999), Leenhouwers et al. (1999), Eissen et al. (2000), Hermesch et al. (2000a, b), Yazdi et al. (2000a, b), Hanenberg et al. (2001), Serenius et al. (2001), Grandinson et al. (2002, 2003), Damgaard et al. (2003), Holm et al. (2004), Serenius and Stalder (2004), Theodoropoulos et al. (2004), Gondret et al. (2005), Suzuki et al. (2005), van Wijk et al. (2005), Gilbert et al. (2007), Hermesch (2007), Bergsma et al. (2008), Engblom et al. (2008, 2009), Hellbrugge et al. (2008a, b), Høøk Presto (2008), Rydhmer et al. (2008), Su et al. (2008), Wallenbeck et al. (2008), Clapperton et al. (2009), Davies et al. (2009), Nejsum et al. (2009), Canario et al. (2010), Gourdine et al. (2010), Lundgren et al. (2010, 2012, 2014)

${ }^{\mathrm{b}}$ See Table 1 for abbreviations 
Statistical analysis

Statistical analyses were performed using the statistical software SAS (version 9.2, SAS Institute Inc., Cary, NC). Descriptive statistics were analysed using procedures MEANS and FREQ, chi-squared $\left(\chi^{2}\right)$ tests were performed using procedure FREQ and analysis of variance was performed using procedure GLM. Residuals of all dependent parameters in the analysis of variance were examined for normal distribution using procedure UNIVARIATE, considering the Shapiro-Wilk test for normality and a normal probability plot, and all were found to be normally distributed.

The ranks ( 1 to 15 ) given to the 15 given traits in part 2 of the questionnaire were transformed into three rank classes: High (ranks 1-5), medium (ranks 6-10) and low (ranks 11-15). Differences in proportion of respondents ranking each trait high, medium and low in the organic and conventional systems were analysed by $\chi^{2}$ tests.

Differences in the desired genetic change for the 15 given traits between organic and conventional farmers were analysed with a statistical model (model 1) including the fixed effects of production system (organic or conventional), production type (piglet producer, slaughter pig producer or integrated piglet and slaughter pig producer), respondent gender (male or female) and the interaction between production system and production type. Respondent age was included as a continuous covariate.

Differences in the desired genetic change for each trait were also analysed in datasets only including the respondents that had ranked that specific trait among the five highest, i.e. excluding the respondents who were not shown the estimated genetic change for that specific trait. These datasets were analysed with a statistical model (model 2) including the fixed effects of production system, production type and respondent gender. Respondent age was included as a continuous covariate.

\section{Results}

The number of farmers that started to complete the questionnaire was 274 (52\% of those invited) and 120 submitted their answers ( $44 \%$ of the 274 farmers who started to complete the questionnaire). Essential information about production system or production type was lacking for 10 of these 120 respondents. Of the 110 respondents included in the statistical analyses, 16
(15\%) represented farms certified according to organic regulations (i.e. $>90 \%$ of organic pig farmers in Sweden answered the questionnaire) and 94 (85\%) represented conventional farms.

The proportion of respondents from farms specialising in piglet production was 25 and $29 \%$ for organic and conventional farms, respectively, and the proportion of respondents from farms specialising in rearing slaughter pigs was 31 and $22 \%$, respectively. The largest proportion of the respondents (44 and $49 \%$ of organic and conventional farms, respectively) represented farms with integrated production, i.e. farms with both piglet and slaughter pig production.

Among the respondents from organic farms, $50 \%$ were female, while $29 \%$ of respondents from conventional farms were female. Respondent age ranged from 26 to 82 years, with mean \pm standard deviation of $49 \pm$ 8.6 years for respondents from organic farms and $47 \pm$ 10.7 years for respondents from conventional farms.

On average, the respondents spontaneously listed (mean \pm standard deviation) $3 \pm 2.0$ traits as important in pigs. Characteristics related to leg health and feed conversion were considered important by more than 50 and $30 \%$ of respondents from organic and conventional farms, respectively. Larger proportions of respondents from conventional farms mentioned growth, sow longevity, fertility and shoulder ulcers as important traits, whereas larger proportions of respondents from organic farms mentioned traits related to leg health, general health and piglet survival as important (Fig. 1).

Analysis based on the respondents' ranking of the 15 given traits revealed that the traits ranked highest among conventional farmers related to piglet production, e.g. piglet survival, fertility, litter size and sow longevity (Fig. 2). The traits ranked highest (by $50 \%$ or more of respondents) among organic farmers were fertility, piglet survival, leg health, feed conversion and disease resistance highly. According to the $\chi^{2}$ tests on differences in rank between organic and conventional respondents, litter size and shoulder ulcers were ranked higher (high or medium) by respondents from conventional farms ( $p=0.002$ and $p=0.018$, respectively). Parasite resistance and roughage consumption were ranked higher by respondents from organic farms $(p<0.001$ and $p=0.014$, respectively).

Based on the desired genetic change expressed in part 3 of the questionnaire, respondents from organic farms rated disease and parasite resistance more highly than respondents from conventional farms (Table 4). 


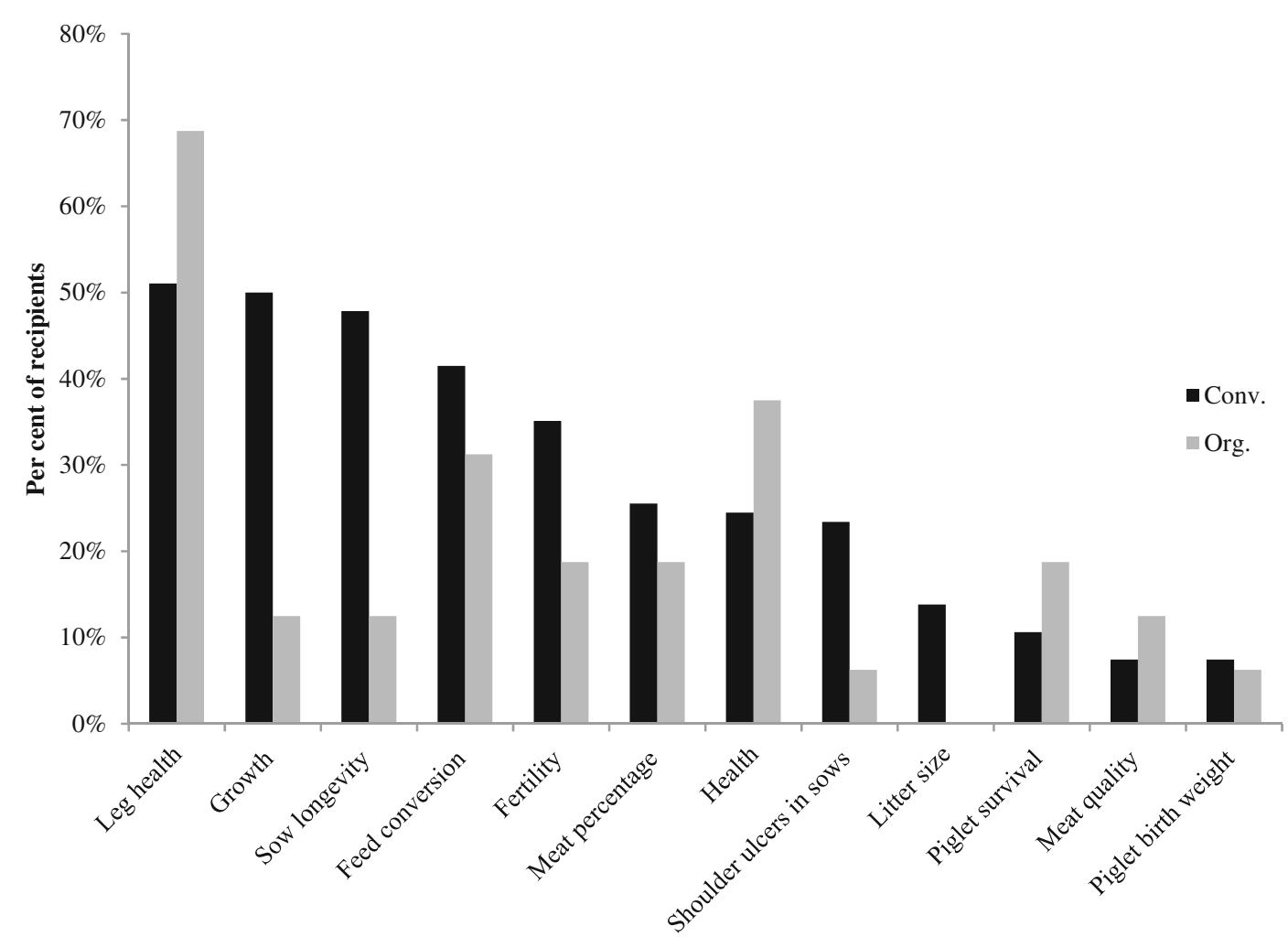

Fig. 1 Percentage of respondents from conventional $(n=94)$ and organic $(n=16)$ farms spontaneously stating pig attributes important in their production (attributes pooled into 12 general classes)

However, when only the respondents ranking these traits among the five highest (i.e. those shown the estimated genetic change for the specific trait) were included in the analysis, this difference disappeared. On average, the weighing performed by respondents from both organic and conventional farms resulted in decreased litter size, meat percentage and meat quality (Table 4). The average estimated genetic change in piglet birth weight and growth (in both piglets and slaughter pigs) was twice as high for respondents from conventional farms as for respondents from organic farms (Table 4). Accordingly, corresponding differences $(p<0.1)$ were found for piglet birth weight and slaughter pig growth in the analyses only including respondents ranking the specific traits highly (ranks 1-5) (Table 5).

Significant levels for the effects included in the statistical model used when analysing the whole dataset (model 1) are presented in Table 6. Production type affected desired genetic change for eight of the 15 traits analysed $(p<0.1)$. Respondent gender affected desired genetic change in feed conversion, slaughter pig growth and meat quality, indicating that production traits were considered more important by men. Age affected desired genetic change in disease resistance, indicating that concern about this trait increases with age. There were interactions $(p<0.1)$ between production system and production type indicating that piglet survival was more important for organic piglet farmers than for other types of organic pig farmers (with integrated production or growing/finishing pig production) and all types of conventional pig farmers. Additionally, disease resistance was more important for organic farmers with integrated production than for all other type of farmers.

\section{Discussion}

The results obtained in this study indicate high emphasis on reproduction and survival traits among conventional pig farmers in Sweden, while organic farmers emphasise health traits more. Furthermore, regardless of production system, Swedish pig farmers consider both production and functional traits, such as feed conversion, growth, reproduction and health, to be important in pig breeding. 


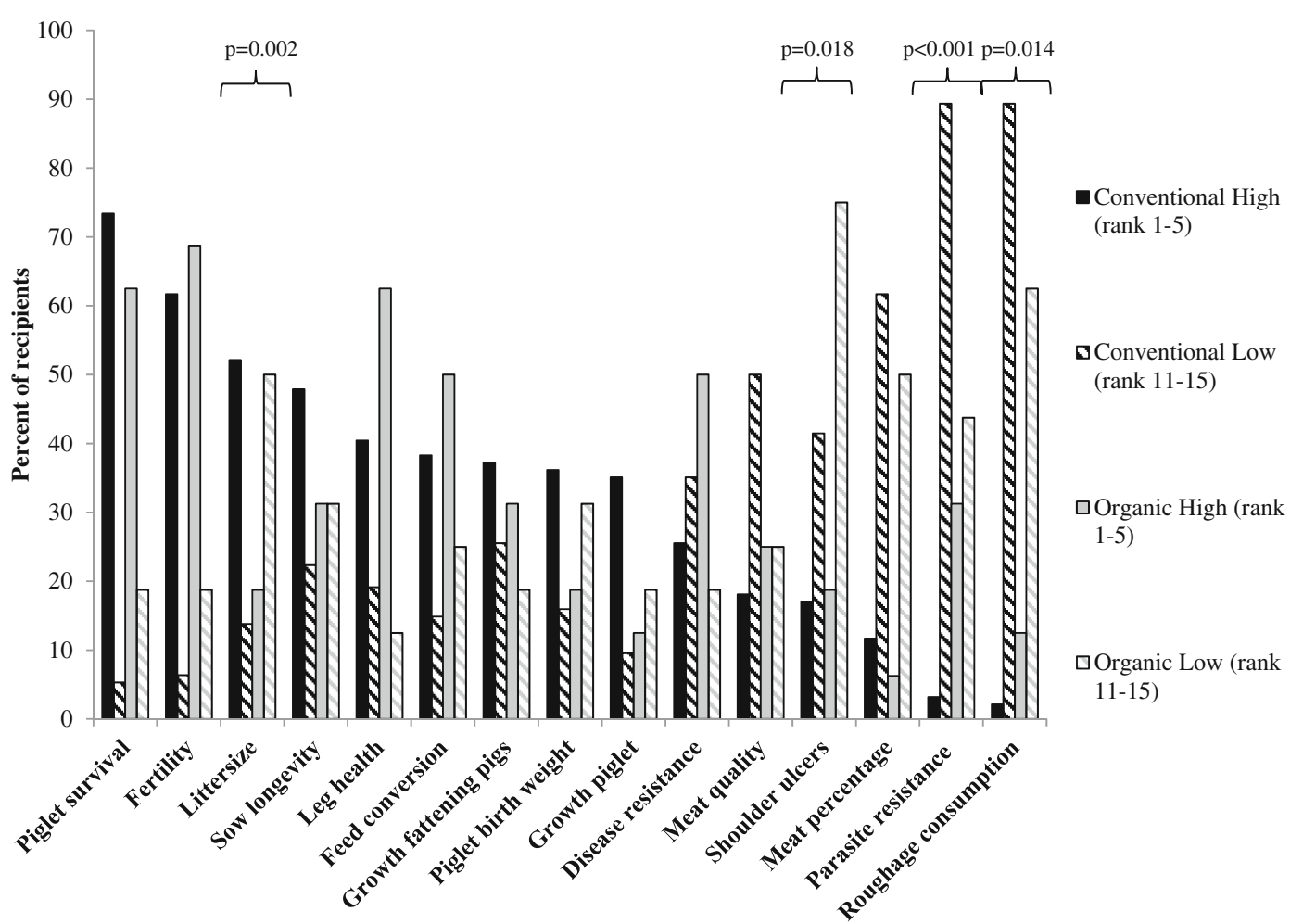

Fig. 2 Proportion of respondents from conventional $(n=94)$ and organic $(n=16)$ farms ranking each trait 'high' (ranks $1-5)$ and 'low' (ranks 1-5) and indications of significant differences in rank

The significant differences found between conventional and organic farmers' ranking of traits were generally associated with low-ranked traits. The relatively higher rank of parasite resistance and roughage consumption among respondents from organic farms is clearly related to differences in production system. Pigs in organic, but not conventional, farms are kept outdoors on pasture, resulting in a higher parasite load in organically reared pigs. Moreover, only organically reared pigs are provided free access to roughage (Wallenbeck 2009). Of the 15 traits that the respondents were asked to rank, roughage consumption and parasite resistance are the only traits not currently included in breeding programmes for the animal material used in the production systems, emphasising the need for different breeding strategies for differing production systems, as suggested previously (Rydhmer et al. 2014). It should be noted, however, that roughage consumption and parasite resistance were only mentioned spontaneously by one respondent each (both from organic farms) in part 1 of the questionnaire. (according to $\chi^{2}$ tests) between production systems. 'Medium' rankings (ranks 6-10) not shown

The difference in emphasis given to shoulder ulcers by organic and conventional farmers could be due to differences in management in these production systems. Bedding with smaller amounts of straw is more common on conventional farms, while deep straw bedding is the most common type of bedding on organic farms. Well-managed deep straw bedding gives a soft surface for sows to lie on, whereas hard surfaces increase the risk of shoulder ulcers (Lundgren 2011).

The reason for the higher ranking of litter size by respondents from conventional farms than those from organic farms is more unclear. It could be argued that litter size has a higher economic impact on conventional farms, as organic pig farmers in Sweden receive a premium (50-100\% higher than conventional) for their produce (Mattsson and Johansson 2010). Another possible reason could be piglet mortality being considered more of an ethical concern and/or more important in communication with consumers by conventional farmers compared with organic farmers.

The estimated desired genetic change showed that organic farmers rate health-related traits such as leg 
Table 4 Average genetic change per generation (least square means (LSM) and standard error (SE)) estimated based on weights given by each respondent in the breeding index in part 3 of the questionnaire

\begin{tabular}{|c|c|c|c|c|c|}
\hline \multirow[t]{2}{*}{ Trait $^{\mathrm{a}}$} & \multicolumn{2}{|c|}{ Organic $(n=16)$} & \multicolumn{2}{|c|}{ Conventional $(n=94)$} & \multirow[t]{2}{*}{$p$ value } \\
\hline & LSM & SE & LSM & SE & \\
\hline Disease resistance & 0.54 & 0.108 & 0.34 & 0.050 & 0.094 \\
\hline Feed conversion & 0.24 & 0.070 & 0.26 & 0.032 & 0.732 \\
\hline Fertility & 0.52 & 0.114 & 0.42 & 0.053 & 0.418 \\
\hline Growth of piglets & 2.07 & 1.393 & 4.28 & 0.645 & 0.154 \\
\hline Growth of slaughter pigs & 4.9 & 4.77 & 10.3 & 2.21 & 0.301 \\
\hline Litter size & -0.17 & 0.059 & -0.09 & 0.027 & 0.204 \\
\hline Leg health & 0.08 & 0.021 & 0.05 & 0.010 & 0.120 \\
\hline Meat quality & -0.01 & 0.064 & -0.08 & 0.030 & 0.296 \\
\hline Meat percentage & -0.17 & 0.078 & -0.15 & 0.036 & 0.811 \\
\hline Parasite resistance & 0.38 & 0.068 & 0.12 & 0.031 & 0.001 \\
\hline Piglet survival & 1.1 & 0.20 & 0.9 & 0.09 & 0.446 \\
\hline Piglet birth weight & 0.01 & 0.005 & 0.02 & 0.003 & 0.326 \\
\hline Roughage consumption & 0.05 & 0.014 & 0.07 & 0.007 & 0.319 \\
\hline Shoulder ulcers in sows & 0.16 & 0.144 & 0.08 & 0.067 & 0.613 \\
\hline Sow longevity & 22.4 & 5.02 & 24.3 & 2.32 & 0.735 \\
\hline
\end{tabular}

Respondents could give weights to the five traits they had ranked highest. All other traits were given zero weight

${ }^{\text {a }}$ See Table 1 for units

health and disease resistance more highly than conventional farmers. One underlying reason for this difference is possibly the high emphasis on preventive health strategies originating from the basic organic farming standards and thus influencing the regulations for organic production (IFOAM 2005). For example, the withdrawal period of products (meat) after medical treatment is double the statutory withdrawal period in Sweden (KRAV 2014). Another reason could be the higher pathogen load and the extensive management practices in organic pig production, which for example put higher pressure on pigs' legs (Heldmer and Lundeheim 2010; Etterlin et al. 2014). The results further indicate a numerically higher average desired genetic change in piglet birth weight and in piglet and slaughter pig growth among respondents from conventional farms compared with those from organic farms. This difference was also clear in the results from the analyses only including respondents ranking the specific trait highly (ranks 15). This higher emphasis on growth among conventional farmers could possibly be due to a higher economic impact of weight and growth in that production system.

The lower emphasis on increased litter size by organic than conventional farmers, which has also been reported in previous studies (Prunier et al. 2014), confirms the discrepancy between breeding goals aiming for high litter size and the goals and ambitions set by the farmers regarding piglet vitality and mortality. The acceptance of a reduction in meat quality and meat percentage is probably due to the lack of connection between payment for carcasses and these traits. It is not difficult for farmers to meet the requirements for top payments from Swedish slaughter companies with the genetic material currently used (the same material is used in conventional and organic production in Sweden, bred for high production in international conventional production systems). It should be noted that meat quality was only ranked $1-5$ by 13 and $24 \%$ of the respondents from conventional and organic farms, respectively. The corresponding figures for meat percentage were 17 and $6 \%$. This indicates that these results were largely correlated genetic responses related to weights allocated to other traits. However, the low ranking of these traits also supports the reasoning above.

The proportions of respondents from farms with piglet production (approximately $25 \%$ ), slaughter pig production (approximately $25 \%$ ) and integrated production (approximately $50 \%$ ) reflected the distribution in 
Table 5 Average genetic change per generation (least square means (LSM) \pm standard error (SE)) estimated based on weights given by each respondent in the breeding index in part 3 of the questionnaire

\begin{tabular}{|c|c|c|c|c|c|c|c|}
\hline \multirow[t]{2}{*}{ Trait } & \multicolumn{3}{|c|}{ Organic } & \multicolumn{3}{|c|}{ Conventional } & \multirow[t]{2}{*}{$p$ value } \\
\hline & LSM & SE & $n$ & LSM & SE & $n$ & \\
\hline Disease resistance & 0.96 & 0.145 & 9 & 0.95 & 0.091 & 26 & 0.936 \\
\hline Feed conversion & 0.39 & 0.083 & 9 & 0.51 & 0.042 & 37 & 0.179 \\
\hline Fertility & 0.85 & 0.112 & 11 & 0.71 & 0.057 & 64 & 0.243 \\
\hline Growth of piglets & 4.3 & 3.17 & 2 & 9.2 & 0.94 & 36 & 0.137 \\
\hline Growth of slaughter pigs & 19.5 & 6.68 & 5 & 30.4 & 4.09 & 37 & 0.070 \\
\hline Litter size & 0.16 & 0.140 & 3 & 0.05 & 0.039 & 54 & 0.449 \\
\hline Leg health & 0.13 & 0.021 & 10 & 0.14 & 0.012 & 42 & 0.834 \\
\hline Meat quality & 0.35 & 0.230 & 4 & 0.11 & 0.143 & 17 & 0.380 \\
\hline Meat percentage & - & - & 1 & - & - & 13 & - \\
\hline Parasite resistance & 0.99 & 0.152 & 6 & 1.1 & 0.21 & 4 & 0.574 \\
\hline Piglet survival & 1.5 & 0.20 & 11 & 1.3 & 0.10 & 75 & 0.528 \\
\hline Piglet birth weight & 0.02 & 0.009 & 3 & 0.04 & 0.003 & 37 & 0.026 \\
\hline Roughage consumption & - & - & 3 & - & - & 3 & - \\
\hline Shoulder ulcers in sows & 0.69 & 0.487 & 3 & 1.19 & 0.276 & 20 & 0.325 \\
\hline Sow longevity & 39.8 & 8.39 & 5 & 40.7 & 3.42 & 50 & 0.919 \\
\hline
\end{tabular}

Respondents could give weights to the five traits they had ranked highest. All other traits were given zero weight. Only respondents ranking the specific trait among the five highest were included in the analysis

${ }^{\text {a }}$ See Table 1 for units

Table 6 Significance levels ( $p$ values) for the effects included in the statistical model (production system (organic or conventional), production type (piglet producer, slaughter pig producer or integrated piglet and slaughter pig production), respondent gender (male or female), respondent age and the interaction between production system and production type. $n=110$

\begin{tabular}{|c|c|c|c|c|}
\hline \multirow[t]{2}{*}{ Trait } & \multicolumn{4}{|l|}{ Effect ( $p$ value) } \\
\hline & Production type & Gender & Age & $\begin{array}{l}\text { Production system } \times \\
\text { production type }\end{array}$ \\
\hline Disease resistance & 0.142 & 0.945 & 0.065 & 0.053 \\
\hline Feed conversion & 0.004 & 0.056 & 0.778 & 0.829 \\
\hline Fertility & 0.004 & 0.441 & 0.232 & 0.158 \\
\hline Growth of piglets & 0.087 & 0.191 & 0.799 & 0.697 \\
\hline Growth of slaughter pigs & 0.016 & 0.072 & 0.617 & 0.906 \\
\hline Litter size & 0.039 & 0.820 & 0.777 & 0.292 \\
\hline Leg health & 0.307 & 0.386 & 0.328 & 0.656 \\
\hline Meat quality & 0.354 & 0.040 & 0.826 & 0.575 \\
\hline Meat percentage & 0.357 & 0.828 & 0.848 & 0.584 \\
\hline Parasite resistance & 0.258 & 0.444 & 0.745 & 0.943 \\
\hline Piglet survival & 0.010 & 0.784 & 0.938 & 0.051 \\
\hline Piglet birth weight & 0.567 & 0.484 & 0.304 & 0.198 \\
\hline Roughage consumption & 0.058 & 0.117 & 0.644 & 0.364 \\
\hline Shoulder ulcers in sows & 0.107 & 0.283 & 0.114 & 0.823 \\
\hline Sow longevity & 0.002 & 0.435 & 0.921 & 0.791 \\
\hline
\end{tabular}


Swedish pig production. It also evened out potential bias towards specific dam or sire traits by the interests of specific groups of farmers.

The proportion of respondents from organic farms was $15 \%$, an overrepresentation of the approximately $2 \%$ of pigs slaughtered in Sweden originating from organic farms. However, considering the low number of organic farmers in Sweden, it was important to include as many of them as possible and we managed to include $>90 \%$, resulting in valid results.

In the statistical model, we adjusted for production type (piglet, slaughter pig or integrated production), as it significantly affected the results for genetic change for feed conversion, fertility, piglet growth, slaughter pig growth, litter size, piglet survival, roughage consumption and sow longevity $(p<0.05)$. All of these traits except roughage consumption is clearly related to either piglet or slaughter pig production. This indicates that our request for respondents to imagine and relate their response to one superior breed that holds all the valuable traits in both dam and sire breeds, and thereby represents the hybrid sows and terminal pigs in commercial production, was not fulfilled. However, it is logical for respondents to answer according to their experiences from their production type and farm, and it was possible to adjust for this effect in the statistical analyses. The aim and design of the advanced internet questionnaire used here was to obtain qualitative rather than quantitative results. Taking the high information load in the answers into account, a response frequency of $44 \%$ among those starting to answer the questionnaire was satisfactory. The selection index used in part 3 of the questionnaire is a novel method for assessment of breeding trait preferences that has previously only been used in one study on preferences for breeding goal traits in dairy cows (Ahlman et al. 2014). One of the advantages with the method is that preferences can be evaluated with a relatively high level of objectivity. One of the disadvantages in the present study was that the farmers could only include the five traits they ranked highest when weighing traits against each other. This meant that they received information on the genetic change that their weighting would cause only for those five traits and not for other traits. The reason for this limitation is that during preliminary testing of the questionnaire, we found that the complexity involved when more than five traits were included influenced the ability and willingness of the respondents to complete the questionnaire, impeding the objective of the study. Moreover, the traits included in the weighing were the five ranked highest by the respondents, so traits ranked 6-15 would have been given low or no weight.

In conclusion, both the conventional and organic farmers studied here wanted increased emphasis on sow longevity and fertility. In order to obtain genetic improvement in those traits, they gave low priority to carcass quality and litter size. Some differences were observed between organic and conventional farmers' preferences for breeding goal traits in pigs, e.g. higher emphasis on fertility and survival traits among conventional farmers and higher emphasis on health traits and piglet survival among organic farmers. Due to the variation in breeding trait preferences found here, we concluded that it is important to take farmers' preferences into consideration when developing future pig breeding strategies.

Acknowledgments The authors thank the Swedish Research Foundation Formas for funding the study. The Swedish Animal Health Service, the Swedish Rural Economy and Agricultural Societies and the Swedish organic certification organisation KRAV are gratefully acknowledged for providing the contact information necessary for distributing the questionnaire. The authors also thank Nils Lundeheim and Helene Hansen Axelsson for valuable inputs during the development of the questionnaire and Mattias Malmgren for programming and administration of the questionnaire. Most of all, the authors want to thank the farmers who participated for taking the time to answer the questionnaire and for contributing their important information and knowledge.

Open Access This article is distributed under the terms of the Creative Commons Attribution 4.0 International License (http:// creativecommons.org/licenses/by/4.0/), which permits unrestricted use, distribution, and reproduction in any medium, provided you give appropriate credit to the original author(s) and the source, provide a link to the Creative Commons license, and indicate if changes were made.

\section{References}

Ahlman T, Ljung M, Rydhmer L, Röcklinsberg H, Strandberg E, Wallenbeck A (2014) Differences in preferences for breeding traits between organic and conventional dairy producers in Sweden. Livest Sci 162:5-14

Bereskin B (1979) Genetic-aspects of feet and leg soundness in swine. J Anim Sci 48(6):1322-1328

Bergsma R, Kanis E, Verstegen MWA, Knol EF (2008) Genetic parameters and predicted selection results for maternal traits related to lactation efficiency in sows. J Anim Sci 86(5): 1067-1080

Boelling D, Groen AF, Sorensen P, Madsen P, Jensen J (2003) Genetic improvement of livestock for organic farming systems. Livest Prod Sci 80(1-2):79-88 
Bonneau M, Antoine-Ilari E, Phatsara C, Brinkmann D, Hviid M, Christiansen MG, Fàbrega E, Rodríguez P, Rydhmer L, Enting I, de Greef K, Edge H, Dourmad J-Y, Edwards S (2011) Diversity of pig production systems at farm level in Europe. J Chain Netw Sci 11(2):115-135

Canario L, Lundgren H, Haandlykken M, Rydhmer L (2010) Genetics of growth in piglets and the association with homogeneity of body weight within litters. J Anim Sci 88(4):1240-1247

Clapperton M, Diack AB, Matika O, Glass EJ, Gladney CD, Mellencamp MA, Hoste A, Bishop SC (2009) Traits associated with innate and adaptive immunity in pigs: heritability and associations with performance under different health status conditions. Genet Sel Evol 41:54

Damgaard LH, Rydhmer L, Lovendahl P, Grandinson K (2003) Genetic parameters for within-litter variation in piglet birth weight and change in within-litter variation during suckling. $\mathrm{J}$ Anim Sci 81(3):604-610

Davies G, Genini S, Bishop SC, Giuffra E (2009) An assessment of opportunities to dissect host genetic variation in resistance to infectious diseases in livestock. Animal 3(3):415-436

Eissen JJ, Kanis E, Kemp B (2000) Sow factors affecting voluntary feed intake during lactation. Livest Prod Sci 64(2-3): $147-165$

Engblom L, Lundeheim N, Strandberg E, Schneider Mdel P, Dalin AM, Andersson K (2008) Factors affecting length of productive life in Swedish commercial sows. J Anim Sci 86(2):432-441

Engblom L, Lundeheim N, Schneider Mdel P, Dalin AM, Andersson K (2009) Genetics of crossbred sow longevity. Animal 3(6):783-790

Etterlin PE, Ytrehus B, Lundeheim N, Heldmer E, Osterberg J, Ekman S (2014) Effects of free-range and confined housing on joint health in a herd of fattening pigs. BMC Vet Res 10:14

Gamborg C, Olsson A, Sandoe P (2005) Farm animal breeding related ethical concerns and tools for implementation CODE EFABAR ethical report

Gilbert H, Bidanel JP, Gruand J, Caritez JC, Billon Y, Guillouet P, Lagant H, Noblet J, Sellier P (2007) Genetic parameters for residual feed intake in growing pigs, with emphasis on genetic relationships with carcass and meat quality traits. $\mathrm{J}$ Anim Sci 85(12):3182-3188

Gondret F, Lefaucheur L, Louveau L, Lebret B, Pichodo X, Le Cozler Y (2005) Influence of piglet birth weight on postnatal growth performance, tissue lipogenic capacity and muscle histological traits at market weight. Livest Prod Sci 93(2): 137-146

Gourdine JL, de Greef KH, Rydhmer L (2010) Breeding for welfare in outdoor pig production: a simulation study. Livest Sci 132(1-3):26-34

Grandinson K, Lund MS, Rydhmer L, Strandberg E (2002) Genetic parameters for the piglet mortality traits crushing, stillbirth and total mortality, and their relation to birth weight. Acta Agric Scand Sect A Anim Sci 52(4):167-173

Grandinson K, Rydhmer L, Strandberg E, Thodberg K (2003) Genetic analysis of on-farm tests of maternal behaviour in sows. Livest Prod Sci 83(2-3):141-151

Hall AD, Hill WG, Bampton PR, Webb AJ (1999) Genetic and phenotypic parameter estimates for feeding pattern and performance test traits in pigs. Anim Sci 68:43-48

Hanenberg E, Knol EF, Merks JWM (2001) Estimates of genetic parameters for reproduction traits at different parities in Dutch Landrace pigs. Livest Prod Sci 69(2):179-186
Heldmer E, Lundeheim N (2010) Gross lesions at slaughter among organic pigs in Sweden. In 21st IPVS Congress. International Pig Veterinary Society, Vancouver

Hellbrugge B, Tolle KH, Bennewitz J, Henze C, Presuhn U, Krieter $\mathrm{J}$ (2008a) Genetic aspects regarding piglet losses and the maternal behaviour of sows. Part 1. Genetic analysis of piglet mortality and fertility traits in pigs. Animal 2(9):1273-1280

Hellbrugge B, Tolle KH, Bennewitz J, Henze C, Presuhn U, Krieter J (2008b) Genetic aspects regarding piglet losses and the maternal behaviour of sows. Part 2. Genetic relationship between maternal behaviour in sows and piglet mortality. Animal 2(9):1281-1288

Hermesch S (2007) Genetic analysis of feed intake in lactating sows. Genetic improvement: making it happen. Proceedings of the Seventeenth Conference of the Association for the Advancement of Animal Breeding and Genetics, Armidale, New South Wales, Australia, 23rd-26th September 2007

Hermesch S, Luxford BG, Graser HU (2000a) Genetic parameters for lean meat yield, meat quality, reproduction and feed efficiency traits for Australian pigs: 2. Genetic relationships between production, carcass and meat quality traits. Livest Prod Sci 65(3):249-259

Hermesch S, Luxford BG, Graser HU (2000b) Genetic parameters for lean meat yield, meat quality, reproduction and feed efficiency traits for Australian pigs: 3. Genetic parameters for reproduction traits and genetic correlations with production, carcass and meat quality traits. Livest Prod Sci 65(3):261-270

Holm B, Bakken M, Klemetsdal G, Vangen O (2004) Genetic correlations between reproduction and production traits in swine. J Anim Sci 82(12):3458-3464

Høøk Presto M (2008) Organic pig meat production. In Acta Universitatis Agriculturae Sueciae. Department of Animal Nutrition and Management, Faculty of Veterinary Medicine and Animal Science, Uppsala

IFOAM (2005) The IFOAM basic standards for organic production and processing. International Federation of Organic Agriculture Movements

Knapp P, Willam A, Solkner J (1997) Genetic parameters for lean meat content and meat quality traits in different pig breeds. Livest Prod Sci 52(1):69-73

KRAV (2014) Regler för KRAV-godkänd produktion. www.krav.se

Leenhouwers JI, van der Lende T, Knol EF (1999) Analysis of stillbirth in different lines of pig. Livest Prod Sci 57(3):243-253

Lundeheim N (1979) Genetic-analysis of respiratory-diseases in pigs. Acta Agric Scand 29(3):209-215

Lundgren H (2011) Genetics of sow performance in piglet production. Acta Universitatis agriculturae Sueciae, Faculty of Veterinary Medicine and Animal Science, Department of Animal Breeding and Genetics 2011(91)

Lundgren H, Canario L, Grandinson K, Lundeheim N, Zumbach B, Vangen O, Rydhmer L (2010) Genetic analysis of reproductive performance in Landrace sows and its correlation to piglet growth. Livest Sci 128(1-3):173-178

Lundgren H, Zumbach B, Lundeheim N, Grandinson K, Vangen O, Olsen D, Rydhmer L (2012) Heritability of shoulder ulcers and genetic correlations with mean piglet weight and sow body condition. Animal 6(1):1-8

Lundgren H, Fikse WF, Grandinson K, Lundeheim N, Canario L, Vangen O, Olsen D, Rydhmer L (2014) Genetic parameters for feed intake, litter weight, body condition and rebreeding success in primiparous Norwegian Landrace sows. Animal $8(2): 175-183$ 
Mattsson B, Johansson A (2010) Economic conditions for organic pig production in Sweden. In European Association for Animal Production. Wageningen Academic, Heraklion

Nejsum P, Roepstorff A, Jorgensen CB, Fredholm M, Goring HHH, Anderson TJC, Thamsborg SM (2009) High heritability for Ascaris and Trichuris infection levels in pigs. Heredity 102(4):357-364

Prunier A, Lubac S, Mejer H, Roepstorff A, Edwards S (2014) Health, welfare and production problems in organic suckling piglets. Org Agric 4(2):107-121

Rydhmer L, Lundeheim N, Canario L (2008) Genetic correlations between gestation length, piglet survival and early growth. Livest Sci 115(2-3):287-293

Rydhmer L, Gourdine J-L, de Greef K, Bonneau M (2014) Evaluation of the sustainability of contrasted pig farming systems: breeding programmes. Animal. doi:10.1017/ S175173111400216X

Serenius T, Stalder KJ (2004) Genetics of length of productive life and lifetime prolificacy in the Finnish Landrace and Large White pig populations. J Anim Sci 82(11):3111-3117

Serenius T, Sevon-Aimonen ML, Mantysaari EA (2001) The genetics of leg weakness in Finnish Large White and Landrace populations. Livest Prod Sci 69(2):101-111

Stern S, Lundeheim N, Johansson K, Andersson K (1995) Osteocondrosis and leg weakness in pigs selected for lean tissue-growth rate. Livest Prod Sci 44(1):45-52

Stewart TB, Hale OM (1988) Losses to internal parasites in swine production. J Anim Sci 66(6):1548-1554

Su G, Sorensen D, Lund MS (2008) Variance and covariance components for liability of piglet survival during different periods. Animal 2(2):184-189
Suzuki K, Irie M, Kadowaki H, Shibata T, Kumagai M, Nishida A (2005) Genetic parameter estimates of meat quality traits in Duroc pigs selected for average daily gain, longissimus muscle area, backfat thickness, and intramuscular fat content. J Anim Sci 83(9):2058-2065

ten Napel J, Meuwissen THE, Johnson RK, Brascamp EW (1998) Genetics of the interval from weaning to estrus in first-litter sows: correlated responses. J Anim Sci 76(4):937-947

Theodoropoulos G, Deligeorgis S, Fegeros K, Papavasiliou D, Rogdakis E (2004) Influence of natural parasitism on meat quality criteria and carcass weight of pigs kept under outdoor farming conditions. Agric Med 134(1):68-76

van Wijk HJ, Arts DJG, Matthews JO, Webster M, Ducro BJ, Knol EF (2005) Genetic parameters for carcass composition and pork quality estimated in a commercial production chain. $\mathrm{J}$ Anim Sci 83(2):324-333

Wallenbeck A (2009) Pigs in organic production — studies of sow behaviour, piglet production and $\mathrm{GxE}$ interactions for performance. Acta Universitatis Agriculturae Sueciae Doctoral Thesis No. 2009:37

Wallenbeck A, Rydhmer L, Thodberg K (2008) Maternal behaviour and perfonnance in first-parity outdoor sows. Livest Sci 116(1-3):216-222

Webb AJ (1989) Genetics of food intake in the pig. Vol. 13. Voluntary food intake of pigs

Yazdi MH, Lundeheim N, Rydhmer L, Ringmar-Cederberg E, Johansson K (2000a) Survival of Swedish Landrace and Yorkshire sows in relation to osteochondrosis: a genetic study. Anim Sci 71:1-9

Yazdi MH, Rydhmer L, Ringmar-Cederberg E, Lundeheim N, Johansson K (2000b) Genetic study of longevity in Swedish Landrace sows. Livest Prod Sci 63(3):255-264 